\title{
Intentional Self-harm Human Poisoning with Agricultural Micronutrient Foliar Spray: From Rural India of Southern Karnataka
}

Sir,

Micronutrients and macronutrients are elements with specific and essential psychological functions in plant metabolism. Compared to macronutrients, micronutrients are essential for plant growth in smaller amounts and play an important role in balanced crop nutrition. ${ }^{[1]}$ Foliar sprays are widely used to supply micronutrients. ${ }^{[2]} \mathrm{We}$ are reporting a patient who presented with intentional self-harm using fatal toxicity of plant micronutrients [Figure 1].

A 36-year-old female, homemaker, was brought to emergency department of a tertiary care hospital with chief complaints of altered sensorium and breathlessness. The patient had a history of alleged consumption of approximately $400 \mathrm{ml}$ poison "Micro Magic -micronutrient foliar spray" (label claims it consisting of $\mathrm{Zn} \mathrm{[3.00 \% ],} \mathrm{Fe}$ [2.00\%], B [0.50\%] [Figure 2], and $\mathrm{Mn}[1.00 \%]) 5$ days ago and was treated at a local hospital. She was initially treated symptomatically with gastric lavage and was started on antibiotic cefoperazone. On the $5^{\text {th }}$ day, her renal and hepatic functions were deteriorated, and she was shifted to tertiary care hospital.

During the admission, a patient was in altered sensorium and was hypoxic (94\% oxygen saturation). Her pulse rate was $108 / \mathrm{min}$ and blood pressure was $150 / 100 \mathrm{mmHg}$. Laboratory data revealed renal failure with urea $207 \mathrm{mg} / \mathrm{dl}$ and creatinine $10 \mathrm{mg} / \mathrm{dl}$ and abnormal liver function (aspartate aminotransferase - $603 \mathrm{IU} / \mathrm{L}$, alkaline phosphatase - $282 \mathrm{IU} / \mathrm{L}$, and alkaline phosphatase (ALP) - $143 \mathrm{IU} / \mathrm{L}$ ) with mild thrombocytopenia $(109,000 \mathrm{mcL})$. Chest X-ray was suggestive of pulmonary edema and cardiac echocardiography

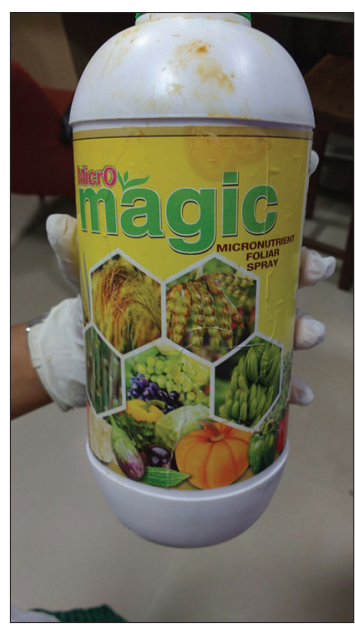

Figure 1: Micronutrient foliar spray showed left ventricular dysfunction. She also had metabolic acidosis $\left(\mathrm{pH}-7.25, \mathrm{PCO}_{2}-19.2, \mathrm{PO}_{2}-80, \mathrm{SpO}_{2}-94 \%\right.$, and $\left.\mathrm{HCO}_{3}-10.7\right)$. Electrocardiography showed sinus tachycardia; however, there was increased troponin $\mathrm{T}(0.299)$ and NT-proBNP (4999) suggestive of myocarditis probably due to Micro Magic consumption.

The patient was treated symptomatically along with supportive and general nursing care in the absence of any known antidote. In view of worsening hypoxia and acidosis, she was ventilated and also underwent multiple episodes of hemodialysis in view of worsening renal failure. Injection levosimendan infusion was started in view of left ventricular dysfunction with low ejection fraction. During a course of hospital stay, the patient developed ventilation-associated pneumonia, for which she was started on injection meropenem. However, patient condition progressively deteriorated and was expired on $7^{\text {th }}$ day of hospital admission due to sepsis and multiorgan dysfunction.

The alleged poison sample was collected for toxicological analysis. No definite results regarding contents were found, except those mentioned on the label.

This case report demonstrates a clear relationship between micronutrient toxicity and the development of multiple organ dysfunctions. A literature search revealed no case reports evidencing such kind of poisonings. The literature does reference similar toxic effects with the heavy metal poisoning with iron, copper, and lead can cause toxic myocarditis. ${ }^{[3]}$ Severe iron overload can manifest as iron-induced myocarditis,

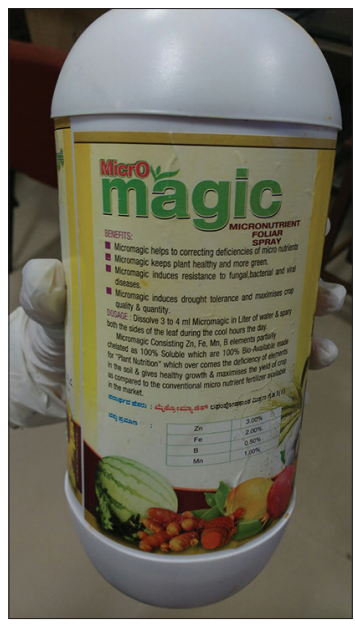

Figure 2: List of spray contents 
cardiac failure, and acute hepatic dysfunction. ${ }^{[4]}$ Renal failure probably associated with other trace elements such as lethal doses of zinc and boron. ${ }^{[5]}$

With the increasing use of micronutrients in agriculture, awareness regarding safety handling and appropriate labeling precautions of such products has to be carried out through proper channels.

\section{Financial support and sponsorship}

Nil.

\section{Conflicts of interest}

There are no conflicts of interest.

Srujitha Marupuru, Girish Thunga, Muralidhar Varma', Sudha Vidyasagar', Pranav Chandak', Sai Mounika Cherukuri ${ }^{1}$

Department of Pharmacy Practice, Manipal College of Pharmaceutical Sciences, Manipal University, 'Department of General Medicine, Kasturba Hospital, Manipal University, Manipal, Karnataka, India

Address for correspondence: Dr. Girish Thunga, Department of Pharmacy Practice, Manipal College of Pharmaceutical Sciences, Manipal - 576 104, Karnataka, India. E-mail: girishthunga77@gmail.com

\section{RefEREnCeS}

1. Römheld V, Marschner H. Function of micronutrients in plants.
Micronutrients in Agriculture. New York, USA: Academic press Elsevier; 1991. p. 297-328.

2. Micronutrient Cropnutrition. Available from: http://www.cropnutrition. com/efu-micronutrients. [Last cited on 2016 Sep 15].

3. Goldenthal MJ, Moe GW. Post-Genomic Cardiology. New York, USA: Academic Press; 2007.

4. McGuigan MA. Acute iron poisoning. Pediatr Ann 1996;25:33-8.

5. Plum LM, Rink L, Haase H. The essential toxin: Impact of zinc on human health. Int J Environ Res Public Health 2010;7:1342-65.

This is an open access article distributed under the terms of the Creative Commons Attribution-NonCommercial-ShareAlike 3.0 License, which allows others to remix, tweak, and build upon the work non-commercially, as long as the author is credited and the new creations are licensed under the identical terms.

\begin{tabular}{|l|l|}
\hline \multicolumn{3}{|c|}{ Access this article online } \\
\hline Quick Response Code: & Website: \\
& www.ijccm.org \\
\cline { 2 - 2 } & \\
\hline
\end{tabular}

How to cite this article: Marupuru S, Thunga G, Varma M, Vidyasagar S, Chandak P, Cherukuri SM. Intentional self-harm human poisoning with agricultural micronutrient foliar spray: From rural India of Southern Karnataka. Indian J Crit Care Med 2017;21:332-3.

(C) 2017 Indian Journal of Critical Care Medicine | Published by Wolters Kluwer - Medknow 